\title{
IV. Description of a new implement called a cultivator
}

\section{Mr. William Lester}

To cite this article: Mr. William Lester (1802) IV. Description of a new implement called a cultivator, Philosophical Magazine Series 1, 13:49, 20-22, DOI: $10.1080 / 14786440208676083$

To link to this article: http://dx.doi.org/10.1080/14786440208676083

曲 Published online: 18 May 2009.

Submit your article to this journal $\pi$

Џll Article views: 2

Q View related articles $\sqsubset$ 
months ago, to $C$. Vauquelin a flafk containing a liquor obtained by the diftillation of vinegar on a large fcale. As C. Pontier was not ignorant that the firft product of the diGtillation of the acetuus acid is aqueous, he feparated it from that which followed. After uniting feveral phlegms of the fame kind, he was much aftonithed to find that thefe phlegms had a very agreeable aromatic odour: having difcovered, by preliminary trials, the properties which gave this product a fimilarity to ethereal liquors, he rectified all the fuppofed phlegns, and by thefe means obtained a peculiar ether, which vauquelin found to be acetic ether completely rectified.

From an identity fo ftriking in the experiments above defcribed, it is evident that there exifts no difference between the conftituent parts of the acetic and acetous acids; that the water, and mucilaginous or extractive matter, are the only two apparent differences obferved in thefe two acids; and, confequently, that there exifts only one acid of vinegar, which being at its maximum of oxygenation, ought, according to the chemical nomenclature, to be diftinguifhed by the name of acetic acid. In future, therefore, there will not exift two different kinds of falts, either by the combination of diftilled vinegar or of raclical vinegar; they will hereafter be fo many products, the names of which mutt be the fame; and hence acetates will exift, and not acetites.

IV. Defiription of a new Implement called a Cultivator. By Mr. WiLliAM LESTER, of Nortbampton*.

\section{sir,}

As the health and luxuriance of corn depend, in a great meafure, on the pulverization of the foll previous to the feed being fown, the Society of Arts will, I am perfuaded, give every encouragement in their power to the introduction of any implement that promifes an abridgement of labour; and as all tenacious foils are pulverized in the beft manner in drye weather, when their particles are the moft disjointed, and their contact broken, the propriety of taking the advantage - of working them in that ftate will be obvious: and at the 'fame time it follows, that an improved implement for the -abridgement of labourwould be a defirable thing in a climate like England, where the feafons are fo uncertain.

F From the Trinfakions of the Sactety for the Eninuratement of Arts, $\because c$. vol. six. - The Socicty's fiver medal was awarded to Mr. Lefter for this invertion. 
In working on a rough fallow, my cultivator thould be fet at its greatelt expanfion, and contracted in proportion as the clods are reduced. I am confident that one man, a boy, and fix horfes, will move as much land in a day, and as effectually, as fix ploughs; I mean land in a fallow ftate, that has been previouny ploughed.

It will be requifice in fome fiates of the foil to alter the breadth of the thares; but of this, I prefume, the farmer will always be a proper judge. By the expantion and contraction of the cultivator, the points of the fhares are, in a fmall degree, moved out of the direct line; but this is fo trifling, that it is no impediment to its working. I am, Sir, Northampton, Feb. 10, 180 r. Your moft obedient fervant, Mr. C. Taylor.

William Lester.

A certificate from Mr. William Shaw, of Cotton End, near Northampton, accompanied this letter; in which he ftates, that he had ufed Mr. Lefter's cultivator upon a turnip fallow laft fummer, and that he believes it to be a very ufeful implement for cultivating the land in a fallow ftate, by its working or fcuffling off feven acres per day, with fix horfes. He adds, that, from its property of contracting and expanding, it is calculated to work the fame land in a rough or fine ftate, by which mean it unites the principles of two implements in one; and, by the index on the axis, it may be worked at any given depth required.

Defcription of Mr. Lefter's Cultivator. (Plate I. fig. 1.)

$A$, the beam.

$B B$, the handles.

$\mathrm{CC}$, a crofs bar of a femicircular form, containing a number of holes, which allow the two bars $D D$, to be placed nearer or further from each other.

$D D$, are two ftrong bars, moveable at one end upon a pivot $\mathrm{E}$, and extending from thence, in a triangular form, to the crofs bar $\mathrm{C}$. In thefe bars are fquare holes, which allow the thares $F$, placed therein, to be fixed to any height required.

The feven thares marked $F$, are thaped at their lower extremities like fmall trowels: the upper parts of them are fquare iron bars.

GG ? are three iron wheels, on which the machine is

$G$, $\int$ moved; they may be raifed or lowered at pleafure.

$\mathrm{H}$, the iron hook to which the fwingle-tree and horfes are to be fixed. 
Philo.Mag. Pl.I.Vol.XIII.
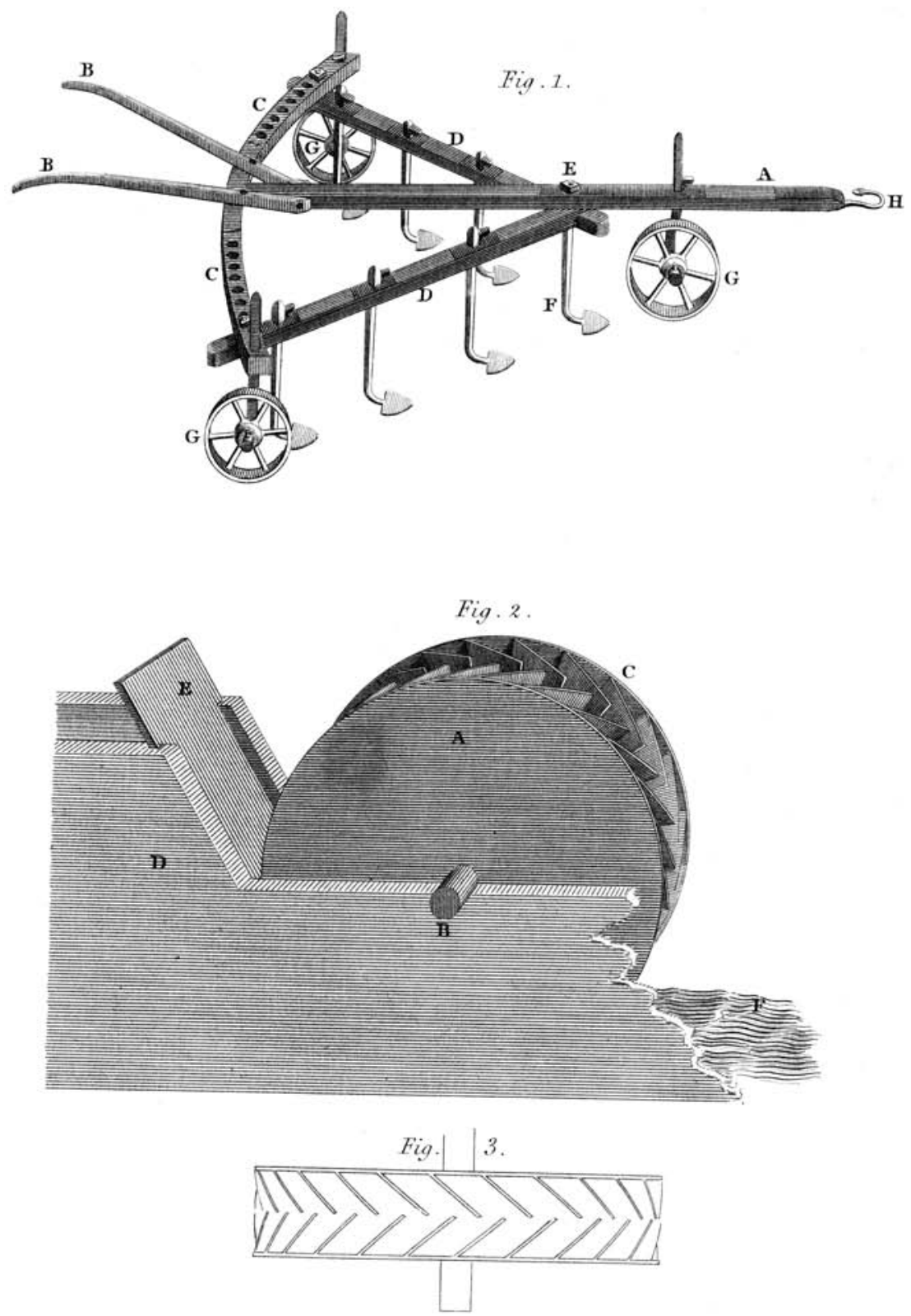
When the machine is firf employed on the land, the bars $D D$ are expanded as much as poffible. As the foil is more loofened, they are brought nearer to the centre: the hares then occupv a lefs fpace, and the foil will confequently be better pulverized.

V. Defcription of a newly invented Under/bot Water-whel. By Mr. J. BesıN T, of Brompton*.

\section{TIR,}

I BEG leave to lay before the Society fome obfervations refpecting the common underfhot water-wheel, and to point out the fuperiority of that of my invention.

ift, In common water-wheels more than half the water paffes from the gate through the wheel, without giving it any affiltance.

$2 \mathrm{dly}$, The floats coming out of the tail-water are refifted with almoft the whole weight of the atmofphere at the inftant they leave the furface of the water.

3 dly, The fame quantity of water which paffed between the floats at the head, muit of courfe pafs between them at the tail, and confequently impede the motion of the wheel.

In the water-wheel of my invention,

Ift, No water can pafs but what acts, with all its force, on the extremity of the wheel.

$2 \mathrm{dly}$, The floats coming out of the water in an oblique direction, prevent the weight of the atmofphere from taking any effect.

3 dly, Although the new water-wheel is heavier than that on the old conftruction, yet it runs lighter on its axis, the water having a tendency to float it.

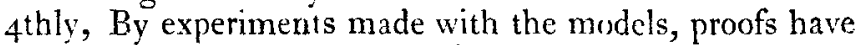
been hown that the new wheel has many advantages over the common wheel; and that, when it works in deep tailwater, it will carry weights in proportion of three to one, fo that it will be particularly ferviceable for tide-mills.

I hope on trial, before the Society, my invention will prove fuccefsful; and am, Sir,

Your obedient fervant,

$$
\text { No. } 26 \text {, Brompton. }
$$

J. BeSANT.

To the Secrotary of the Socity of Arts, EDc.

From tie Tianfakions of the Ssiets for the Enoturgentent of Arts,

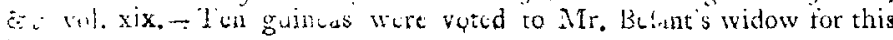
iturentor?

Repeated 